\title{
Prevalence and Socio-Demographic Determinants of Depression in Women: A Comparison between Pre-Menopausal and Post-Menopausal Attendees of the General Outpatient Department in Fmc Lokoja
}

\author{
Obianma Nneka Onya ${ }^{1 *}$, Chinenye Otorkpa ${ }^{2}$ \\ ${ }^{1}$ Department of Family Medicine, University of Port Harcourt Teaching Hospital, Port Harcourt, Nigeria \\ ${ }^{2}$ Federal Medical Centre, Lokoja, Nigeria \\ Email: *obianmaonya@yahoo.co.uk, chinenyeotorkpa@gmail.com
}

How to cite this paper: Onya, O.N. and Otorkpa, C. (2018). Prevalence and Socio-Demographic Determinants of Depression in Women: A Comparison between Pre-Menopausal and Post-Menopausal Attendees of the General Outpatient Department in Fmc Lokoja. Open Journal of Depression, 7, 51-59.

https://doi.org/10.4236/ojd.2018.73004

Received: June 16, 2018

Accepted: August 28, 2018

Published: August 31, 2018

Copyright $\odot 2018$ by authors and Scientific Research Publishing Inc. This work is licensed under the Creative Commons Attribution International License (CC BY 4.0).

http://creativecommons.org/licenses/by/4.0/

\begin{abstract}
Introduction: Globally, the burden of depression is on the increase especially among women. The increased prevalence of depression correlates with hormonal changes in women, suggesting that female hormonal fluctuations may be a trigger for depression. Hence this study sought to determine the prevalence and socio-demographic pattern of depression among pre- and post-menopausal women. Methodology: A cross-sectional design comprising of pre- and post-menopausal women attending the General Outpatient Department of the Federal Medical Centre in Lokoja, North-Central region of Nigeria was employed in this study. Data on depression were collection using the Center for Epidemiologic Study Depression (CES-D) questionnaire, a validated and reliable tool for assessment of depression. Descriptive and inferential statistics were performed using Centers for Disease Control and Prevention (CDC) Epi Info version 7. Statistical significance was set at level of 0.05. Results: A total of 277 pre-menopausal and 103 post-menopausal women were involved in the study. The prevalence of depression was higher among post-menopausal women $(45.6 \%)$ in comparison to pre-menopausal women $(35.4 \%)$. There was no significant relationship between demographic characteristics and depression in both groups of the study $(p>0.05)$. Conclusion: This study noted that unlike the pre-menopausal population, almost half of the post-menopausal women had depression. Hence, routine screening for depression among post-menopausal women is advocated for timely intervention irrespective of their socio-demographic status.
\end{abstract}




\section{Keywords}

Premenopause, Postmenopause, Depression, Outpatient

\section{Introduction}

Depression is a common illness worldwide with an estimated 350 million people affected (WHO, 2012). It may constitute a serious health condition, chronic and debilitating in nature thereby jeopardizing the functioning and quality of life of the affected individual.

In this group of people, family and occupational dysfunction can be risk factors for suicide. ${ }^{2}$ Over 800,000 people die due to suicide every year (Zhou et al., 2014).

The prevalence of major depression is higher in women than in men; with available data showing a 1.7-fold greater incidence in women. It is predicted to be the leading cause of disease burden by 2030 (Coryell, 2011).

The increased prevalence of depression correlates with hormonal changes in women, particularly during puberty, prior to menstruation, following pregnancy and at perimenopause, suggesting that female hormonal fluctuations may be a trigger for depression. Studies show that estrogen may have a protective effect on the pathology that underlies depression, and that decreases in estrogen may increase the risk for depression as seen in menopause (Coryell, 2011).

Menopause is the physiologic or iatrogenic cessation of the menstrual period due to decreasing ovarian function (Dalal \& Agarwal, 2015).

Staging of reproductive ageing in women has been done in relation to the final menstrual period, which is regarded as stage 0 (Practice Committee of American Society for Reproductive Medicine, 2008; Kessler \& Bromet, 2013).

A prevalence rate of $24.7 \%$ for depression amongst post-menopausal women was found in Turkey (Unsal et al., 2011), which is much lower than $59.8 \%$ reported in Iran (Afshar et al., 2015). However, a study in China, gave a prevalence rate of $11.4 \%$ (Zang et al., 2016), while Timiz et al. reported a rate of $23.2 \%$ and $56.9 \%$ among perimenopausal and postmenopausal women, respectively (Timur \& Sahin, 2010), which is higher than the $4.3 \%$ depression prevalence recorded in Benin, Nigeria (Ande et al., 2011).

A review of studies on depression and menopause report that the likelihood of depressed mood in the menopausal transition is approximately three times greater compared with that during pre-menopause. Other risk factors for depressed mood in perimenopausal women include poor sleep, hot flashes, stressful or negative life events, employment status, age, and race (Freeman, 2010). In addition, history of severe premenstrual syndrome or postpartum blues, ethnicity, history of stressful live events, past history of depression, body mass index and socioeconomic status are implicated (Freeman et al., 2006). Women are more likely to have a diagnosis of major depression in the menopausal transition compared with premenopausal women (Soares, 2013; Yen et al., 2009; Bashar et 
al., 2017). The causal relationships between depressive symptoms and menopause, however, are unclear; a particular controversy has been established around the question whether depressed mood is caused by psychological factors related to aging or whether ovarian hormonal changes may play a significant role in its occurrence (Soares, 2010).

The higher prevalence of depression in post-menopausal women may also be influenced by factors like; losing the role of being a mother, husband's death, negative attitudes toward menopause, and long term menopause. Psychosocial events such as changes in relationships with children, marital status, and other life events have been reported to be related factors to depression during menopause. High levels of stress and anxiety like unpleasant life events are capable of exacerbating the symptoms of menopause and depression (Afshar et al., 2015).

The pre-menopausal phase, which corresponds to the reproductive stage, however, has also been associated with documented depressive entities: The premenstrual dysphoric disorder (PMDD), depression in pregnancy, and post -partum depression (Okeke et al., 2013).

PMDD- which affects approximately $3 \%$ to $9 \%$ of pre-menopausal women and starts typically during the teens (Okeke et al., 2013) is a severe form of PMS, or Premenstrual exacerbation of depression, which is a worsening of symptoms of an ongoing mood disorder during the premenstrual period. Up to $75 \%$ of women of reproductive age experience some physical, and emotional symptoms attributed to the premenstrual phase of the menstrual cycle, but only $20 \%$ report severe symptoms warranting treatment.

According to a study conducted in Northern Western Nigeria, the socio-demographic correlates of depression included age, sex, marital status, and educational level. It reported that there was a statistically significant relationship between increasing age and depression. Depression was also more prevalent in the female sex, amongst married people, and people with low socioeconomic status. It then reported a lack of relationship between depression and employment status, as well as a positive family history of mental illness. It further summarized that a depressed person was more likely to be over 40 years, female, married, having low level of education and suffering from a chronic medical condition (Salihu \& Udofia, 2016).

This is somewhat similar to another study done in Ilorin, North Central Nigeria, which recorded a strong statistical association between depression and age group, sex, marital status, level of education, occupation, and monthly income. However, religion and ethnicity had no statistically significant relationship with depression in this study (Shittu et al., 2014).

It would therefore be of tremendous benefit to determine the relationship between socio-demographic factors and depression prevalence among pre and post-menopausal women in Lokoja.

\section{Materials and Methods}

The study was conducted in the General Outpatient Department (GOPD) of the 
FMC Lokoja among 380 female attendees (using the Fisher's statistical formula) who met the inclusion criteria of being female and $\geq 18$ years. This was done between January and March 2017. A cross-sectional descriptive hospital-based study was carried out from which severely ill women, those with surgically-induced menopause, those on antidepressants and hormonal replacement therapy were excluded.

Using the ratio of pre-menopausal women to post-menopausal women observed in the GOPD (2.7:1), sample size attained from calculation was distributed accordingly. Systematic random sampling technique was used. The calculation of sample size employed the formula for cross-sectional studies using the 95\% significant level, prevalence of depression of 59.1\% reported by Afolabi et al. (Afolabi et al., 2008), and precision of 5\% to attain a value of 380 . Hence 277 and 103 pre- and post-menopausal women were involved in the study. Simple random sampling using a sampling frame comprising of the study population of interest was used in the selection of respondents for the study.

Data were collected using a semi-structured and interviewer-administered questionnaire, which comprised of demographic section and depression assessment. The demographic characteristics of interest were age, marital status and education level. Depression assessment was done using Center for Epidemiologic Study Depression (CES-D), a widely-used tool with good validity and reliability-Cronbach's Alpha of 0.79 (Ref-Peltzer et al., 2013). The minimum and maximum scores on CES-D are 0 and 60 respectively. A score of greater than 21 indicates presence of depression. Data were analyzed using the United States Centers for Disease Control and Prevention (CDC) Epi Info version 7. Descriptive statistics involved data presentation using absolute and relative frequencies while inferential statistics employed the Pearson's Chi-Square test to compare the differences in proportions across pre- and post-menopausal women. The strength of association between category of women and depression was determined using the odds ratio. Confidence interval was calculated at 95\% level and statistical significance set at 0.05 .

Ethical approval was obtained from the Ethical Review Board of the Federal Medical Centre, Lokoja prior to commencement of the study. Informed consent, justice, non-maleficence, beneficence and confidentiality were upheld in the study. Attendees identified with depression and reasons for primary encounter were managed appropriately.

\section{Results}

There were a total of 380 women in this study, of which 277 (72.9\%) were pre-menopausal while $103(27.1 \%)$ were post-menopausal. The minimum and maximum ages of the respondents were 18 years and 60years respectively. Among pre-menopausal respondents, those aged less than 30 years constituted the highest proportion (42.2\%) while in the post-menopausal group, women aged 51 - 60 years had the highest proportion (33.3\%). Concerning marital status 
and educational level characteristics, there were significant differences in the proportions of these demographic characteristics across the categories of women $(p<0.05)$ (Table 1$)$.

Forty-seven of the 103 post-menopausal women (45.6\%) had depression while 93 of the 277 pre-menopausal women (34.4\%) had depression. The prevalence of depression was higher among post-menopausal women in comparison to pre-menopausal women but this difference was not significant $(p>0.05)$. Post-menopausal women were 1.5 times more likely to be depressed than pre-menopausal women [Odds ratio (95\% Confidence Interval) $=1.5(0.9-2.5)$ ] (Table 2).

The prevalence of depression was highest among older aged women in both

Table 1. Socio-demographic characteristics of pre-and post-menopausal women in the study.

\begin{tabular}{|c|c|c|c|c|c|}
\hline $\begin{array}{l}\text { Socio-demograp } \\
\text { hic variables }\end{array}$ & $\begin{array}{c}\text { Pre-menopausal } \\
\mathrm{N}=277 \\
\mathrm{n}(\%)\end{array}$ & $\begin{array}{c}\text { Post-menopausal } \\
\mathrm{N}=103 \\
\mathrm{n}(\%)\end{array}$ & $\begin{array}{c}\text { Total } \\
\mathrm{N}=380 \\
\mathbf{n}(\%)\end{array}$ & Chi-Square & p-value \\
\hline \multicolumn{6}{|l|}{ Age category } \\
\hline$\leq 30$ years & $117(42.2 \%)$ & $0(0.0 \%)$ & $117(30.8 \%)$ & & \\
\hline $31-40$ years & $115(41.5 \%)$ & $5(4.8 \%)$ & $120(31.6 \%)$ & 261.1 & $<0.001^{*}$ \\
\hline $41-50$ years & $45(16.3 \%)$ & $32(31.1 \%)$ & $77(20.3 \%)$ & & \\
\hline$>50$ years & $0(0.0 \%)$ & $66(64.1 \%)$ & $66(17.3 \%)$ & & \\
\hline \multicolumn{6}{|l|}{ Marital status } \\
\hline Single & $83(30.0 \%)$ & $3(2.9 \%)$ & $86(22.6 \%)$ & & \\
\hline Married & $158(57.0 \%)$ & $51(49.5 \%)$ & $209(55 \%)$ & 65.56 & $<0.001^{*}$ \\
\hline Separated & $29(10.5 \%)$ & $37(35.9 \%)$ & $66(17.4 \%)$ & & \\
\hline Widowed & $7(2.5 \%)$ & $12(11.7 \%)$ & $19(5 \%)$ & & \\
\hline \multicolumn{6}{|l|}{ Education } \\
\hline None & $5(1.8 \%)$ & $16(15.5 \%)$ & $21(5.5 \%)$ & & \\
\hline Primary & $28(10.1 \%)$ & $32(31.1 \%)$ & $60(15.8 \%)$ & 58.35 & $<0.001^{*}$ \\
\hline Secondary & $116(41.9 \%)$ & $29(28.2 \%)$ & $145(38.2 \%)$ & & \\
\hline Tertiary & $128(46.2 \%)$ & $26(25.2 \%)$ & $154(40.5 \%)$ & & \\
\hline
\end{tabular}

*Statistically significant.

Table 2. Prevalence of depression among pre- and post-menopausal women.

\begin{tabular}{cccc}
\hline \multirow{2}{*}{ Category of women } & \multicolumn{2}{c}{ Depression } & \multirow{2}{*}{ Total } \\
\cline { 2 - 3 } & Yes & No & \\
\hline Post-menopausal & $47(45.6 \%)$ & $56(54.4 \%)$ & $103(100.0 \%)$ \\
Pre-menopausal & $98(34.4 \%)$ & $179(65.6 \%)$ & $277(100.0 \%)$ \\
Total & $\mathbf{1 4 5 ( 3 8 . 2 \% )}$ & $235(61.8 \%)$ & $380(100.0 \%)$ \\
\hline
\end{tabular}

Odds ratio $(95 \%$ Confidence Interval $)=1.5(0.9-2.5)$; Chi-Square $=3.344 ; \mathrm{p}$-value $=0.067$. 
pre-menopausal and post-menopausal categories of women. Pre-menopausal women who were widowed had the highest prevalence of depression $(57.1 \%)$, while among the post-menopausal women, married women had the highest prevalence rate $(56.9 \%)$. In both pre- and post-menopausal women, those with no level of education had the highest rate of depression as shown in Table 3 . The studied socio-demographic characteristics of the women, therefore showed no significant relationship with depression in both groups of women $(p>0.05)$.

\section{Discussion}

The study has demonstrated that even though there was a significant difference in the distribution of the socio-demographic characteristics (age, marital \& educational status) in both pre-menopausal and post-menopausal groups, those differences did not have a significant association with depression prevalence in either of the groups ( $p=0.1136,0.7394,0.5032,0.1249,0.6923$ and 0.7833$)$. These

Table 3. Relationship between socio-demographic factors and depression among preand post-menopausal women.

\begin{tabular}{|c|c|c|c|c|}
\hline \multirow[b]{2}{*}{ Socio-demographic variables } & \multicolumn{2}{|c|}{ Pre-menopausal } & \multicolumn{2}{|c|}{ Post-menopausal } \\
\hline & $\begin{array}{l}\text { Depressed } \\
\text { n (\%) }\end{array}$ & $\begin{array}{c}\text { Not Depressed } \\
n(\%)\end{array}$ & $\begin{array}{l}\text { Depressed } \\
\text { n (\%) }\end{array}$ & $\begin{array}{c}\text { Not Depressed } \\
\mathrm{n}(\%)\end{array}$ \\
\hline \multicolumn{5}{|l|}{ Age category } \\
\hline$\leq 30$ years & $45(38.5 \%)$ & $72(61.5 \%)$ & $0(0.0 \%)$ & $0(0.0 \%)$ \\
\hline $31-40$ years & $33(28.7 \%)$ & $82(71.3 \%)$ & $2(40.0 \%)$ & $3(60.0 \%)$ \\
\hline $41-50$ years & $20(44.4 \%)$ & $25(55.6 \%)$ & $13(40.6 \%)$ & $19(59.4 \%)$ \\
\hline \multirow[t]{2}{*}{$>50$ years } & $0(0.0 \%)$ & $0(0.0 \%)$ & $32(48.5 \%)$ & $34(51.5 \%)$ \\
\hline & \multicolumn{2}{|c|}{$\begin{array}{c}\text { Chi square }=4.351 \\
p \text {-value }=0.1136\end{array}$} & \multicolumn{2}{|c|}{$\begin{array}{c}\text { Chi square }=0.6038 \\
p \text {-value }=0.7394\end{array}$} \\
\hline \multicolumn{5}{|l|}{ Marital status } \\
\hline Single & $30(36.1 \%)$ & $53(63.9 \%)$ & $1(33.3 \%)$ & $2(66.7 \%)$ \\
\hline Married & $52(32.9 \%)$ & $106(67.1 \%)$ & $29(56.9 \%)$ & $22(43.1 \%)$ \\
\hline Separated & $12(41.4 \%)$ & $17(58.6 \%)$ & $14(37.8 \%)$ & $23(62.2 \%)$ \\
\hline \multirow[t]{2}{*}{ Widowed } & $4(57.1 \%)$ & $3(42.9 \%)$ & $3(25.0 \%)$ & $9(75.0 \%)$ \\
\hline & \multicolumn{2}{|c|}{$\begin{array}{c}\text { Chi square }=2.349 \\
p \text {-value }=0.5032\end{array}$} & \multicolumn{2}{|c|}{$\begin{array}{c}\text { Chi square }=5.741 \\
p \text {-value }=0.1249\end{array}$} \\
\hline \multicolumn{5}{|l|}{ Educational level } \\
\hline None & $3(60.0 \%)$ & $2(40.0 \%)$ & $9(56.2 \%)$ & $7(43.8 \%)$ \\
\hline Primary & $9(32.1 \%)$ & $19(67.9 \%)$ & $15(46.9 \%)$ & $17(53.1 \%)$ \\
\hline Secondary & $41(35.3 \%)$ & $75(64.7 \%)$ & $12(41.4 \%)$ & $17(58.6 \%)$ \\
\hline \multirow[t]{2}{*}{ Tertiary } & $45(35.2 \%)$ & $83(64.8 \%)$ & $11(42.3 \%)$ & $15(57.7 \%)$ \\
\hline & \multicolumn{2}{|c|}{$\begin{array}{c}\text { Chi square }=1.457 \\
p \text {-value }=0.6923\end{array}$} & \multicolumn{2}{|c|}{$\begin{array}{c}\text { Chi square }=1.074 \\
p \text {-value }=0.7833\end{array}$} \\
\hline
\end{tabular}


findings are at variance with other studies done in Kano and Ilorin, Nigeria which found a significant association between marital status, age, educational level and depression prevalence in women (Salihu \& Udofia, 2016; Shittu et al., 2014). Worthy of note, however, is the fact that the older women in both age groups were more prone to having depression; that the widowed pre-menopausal and married post-menopausal women had increased depression prevalence; and that in both groups, lack of formal education was associated with greater depression prevalence. The plausible explanation for the above findings is that different tools were used to diagnose depressive illness. In this study married women were more prone to having depression possibly due to family dysfunctional constituting an additional psychological stressor that may predispose the women to having depression. Lack of formal education could lead to having very stressful jobs with poorer remuneration, thereby contributing to psychological stress that could trigger off depression.

The prevalence of depression in the post-menopausal category (45.67\%) was higher than that of the premenopausal group (35.4\%) even though the difference was not statistically significant. Most other studies found a significantly higher depression prevalence among the post-menopausal group in comparison with the premenopausal category (Timur \& Sahin, 2010; Ande, 2011; Freeman, 2010; Freeman et al., 2006). This could be as a result of not taking into consideration the presence and severity of menopausal symptoms in this study.

\section{Conclusion}

The study demonstrates an increasing prevalence of depression from premenopausal to postmenopausal phases, thereby illustrating the complexities of reproduction-related "windows of vulnerability" which pose a challenge to physicians dedicated to catering for women's health across the lifespan. It underscores the need for routine depression screening especially as women approach menopause, irrespective of their socio-demographic circumstances.

\section{Limitation}

The study was not able to exclude other confounding variables as logistic regression was not done.

\section{Author Contributions}

The first and corresponding author analysed the data, wrote the introduction, methodology, and results. The second author collected the data and wrote the discussion and conclusion.

\section{Conflicts of Interest}

The authors declare no conflicts of interest regarding the publication of this paper. 


\section{References}

Afolabi, M. O., Abioye-Kuteyi, E. A., Fatoye, F. O., Bello, I. S., \& Adewuya, A. O. (2008). Pattern of Depression among Patients in a Nigerian Family Practice Population. South African Family Practice, 50, 63a-e. https://doi.org/10.1080/20786204.2008.10873701

Afshar, P., Manochehri, S., Tadayon, M., Kianfar, M., \& Haghighizade, M. (2015). Prevalence of Depression in Post Menopausal Women. Jundishapur Journal of Chronic Disease Care, 4, 12-15.

Ande, A. B., Omu, O. P., Ande, O., \& Olagbuji, N. B. (2011). Features and Perceptions of Menopausal Women in Benin City Nigeria. Annals of African Medicine, 10, 300. https://doi.org/10.4103/1596-3519.87048

Bashar, M. I., Ahmed, K., Uddin, M. S., Ahmed, F., Emran, A., \& Chakraborty, A. (2017). Depression and Quality of Life among Postmenopausal Women in Bangladesh: A Cross-Sectional Study. Journal of Menopausal Medicine, 23, 172-181. https://doi.org/10.6118/jmm.2017.23.3.172

Coryell, W. (2011). Mood Disorders. In R. S. Porter (Ed.), The Merck Manual of Diagnosis and Therapy (19th ed., p. 1539). New Jersey: Merck Sharp and Dohme.

Dalal, P. K., \& Agarwal, M. (2015). Postmenopausal Syndrome. Indian Journal of Psychiatry, 57, S222-S232. https://doi.org/10.4103/0019-5545.161483

Freeman, E. W. (2010). Associations of Depression with the Transition to Menopause. Journal of North American Menopause society, 17, 823-827. https://doi.org/10.1097/gme.0b013e3181db9f8b

Freeman, E. W., Samuel, M. D., Lin, H., \& Nelson, D. B. (2006). Associations of Hormones and Menopausal Status with Depressed Mood in Women with No History of Depression. Archives of General Psychiatry, 63, 375-382.

https://doi.org/10.1001/archpsyc.63.4.375

Kessler, R. C., \& Bromet, E. J. (2013). The Epidemiology of Depression across Cultures. Annual Review of Public Health, 34, 119-138. https://doi.org/10.1146/annurev-publhealth-031912-114409

Okeke, T. C., Anyaehie, U. B., \& Ezenyeaku, C. C. (2013). Premature Menopause. Annals of Medical and Health Sciences, 3, 90-95. https://doi.org/10.4103/2141-9248.109458

Practice Committee of American Society for Reproductive Medicine (2008). The Menopausal Transition. The American Society for Reproductive Medicine, Birmingham, Alabama, 90, S61-65.

Ref-Peltzer, K., Pengpid, S., Olowu, S., \& Olasupo, M. (2013). Depression and Associated Factors among University Students in Western Nigeria. Journal of Psychology in Africa, 23, 459-465. https://doi.org/10.1080/14330237.2013.10820652

Salihu, A. S., \& Udofia, O. (2016). Prevalence and Associated Factors of Depression among General Outpatients in a Tertiary Institution in Kano, North-Western Nigeria. Open Journal of Psychiatry, 6, 228-236. https://doi.org/10.4236/ojpsych.2016.63028

Shittu, R. O., Odeigah, L. O., Issa, B. A., Olanrewaju, G. T., Mahmoud, A. O., \& Sanni, M. A. (2014). Association between Depression and Sociodemographic Factors in a Nigerian Family Practice setting. Open Journal of Depression, 3, 18-23. https://doi.org/10.4236/ojd.2014.31006

Soares, C. N. (2010). Can Depression Be a Menopause-Associated Risk? BMC Medicine, 8, 79. https://doi.org/10.1186/1741-7015-8-79

Soares, C. N. (2013). Depression in Peri and Postmenopausal Women: Prevalence, Pathophysiology and Pharmacological Management. Drugs and Aging, 30, 677-685.

https://doi.org/10.1007/s40266-013-0100-1 
Timur, S., \& Sahin, N. H. (2010). The Prevalence of Depression Symptoms and Influencing Factors among Perimenopausal and Postmenopausal Women. Menopause, 17, 545-551.

Unsal, A., Tozun, M., \& Ayranci, U. (2011). Prevalence of Depression among Post Menopausal Women and Related Characteristics. Climacteric, 14, 244-251. https://doi.org/10.3109/13697137.2010.510912

World Health Organization WHO (2012). Depression. Fact Sheet No. 369. Geneva: World Health Organization.

Yen, J. Y., Yang, M. S., Wang, M. H., Lai, C., \& Fang, M. S. (2009). The Association between Menopausal Syndrome and Depression during Pre, Peri and Postmenopausal Period among Taiwanese Female Aborigines. Psychiatry and Clinical Neurosciences, 63, 678-684. https://doi.org/10.1111/j.1440-1819.2009.02001.X

Zang, H., He, L., Chen, Y., Ge, J., \& Yao, Y. (2016). The Association of Depression Status with Menopause Symptoms among Rural Midlife Women in China. African Health Sciences, 16, 97-104. https://doi.org/10.4314/ahs.v16i1.13

Zhou, X., Bi, B., Zheng, L., Li, Z., Yang, H., Song, H., et al. (2014). The Prevalence and Risk Factors for Depression Symptoms in a Rural Chinese Sample Population. PLoS ONE, 9, e99692. https://doi.org/10.1371/journal.pone.0099692 